\title{
Mechanisms of systemic adaptation to univentricular Fontan conversion
}

\author{
Cynthia D. Myers, MD, ${ }^{\mathrm{a}}$ Kimberly Ballman, BA, ${ }^{\mathrm{a}}$ Lindsay E. Riegle, MD, ${ }^{\mathrm{a}}$ Kelly D. Mattix, MD, ${ }^{\mathrm{a}}$ \\ Kenneth Litwak, DVM, PhD, ${ }^{b}$ and Mark D. Rodefeld, MD $^{\mathrm{a}}$
}

\begin{abstract}
Objective: After univentricular Fontan conversion, systemic venous pressure serves as the sole driving force for transpulmonary blood flow. Consequently, systemic venous return is markedly altered and ventricular filling is subnormal. The mechanisms and time course of systemic adaptation to Fontan conversion are incompletely understood. We hypothesized that acute elevation in systemic venous pressure induces an adaptive response similar to conversion to a univentricular Fontan circulation.
\end{abstract}

\begin{abstract}
Methods: Adjustable vessel occluders were placed around the superior and inferior vena cavae in juvenile sheep. After 1-week recovery, occluders were tightened to acutely increase and maintain systemic venous pressure at 15 $\mathrm{mm} \mathrm{Hg}(\mathrm{n}=6)$, simulating 1-stage Fontan conversion. Control animals $(\mathrm{n}=4)$ received identical surgery, but venous pressure was not manipulated.

Results: Cardiac index decreased significantly $\left(3.9 \pm 1.0 \mathrm{~mL} / \mathrm{min} / \mathrm{m}^{2}\right.$ to $\left.2.7 \pm 0.7 \mathrm{~mL} / \mathrm{min} / \mathrm{m}^{2}, P<.001\right)$ and then normalized to control at 2 weeks. Circulating blood volume increased $(100 \pm 9.4 \mathrm{~mL} / \mathrm{kg}$ vs $85.5 \pm 8.4$ $\mathrm{mL} / \mathrm{kg}, P=.034)$ as a persistent response. Cardiac reserve improved and was not different from control by week 3. Resting heart rate decreased in both groups. Oxygen extraction (arteriovenous oxygen difference) and neurohormonal mediators increased transiently and then normalized by week 2 .

Conclusions: Adaptation to global elevation in systemic venous pressure to Fontan levels is complete within 2 weeks. Increased blood volume and reduced heart rate are persistent responses. Increased oxygen extraction and neurohormonal up-regulation are temporary responses that normalize with recovery of cardiac output. With improved physiologic understanding of systemic adaptation to Fontan conversion, approaches to single-ventricle palliation can be more objectively assessed and optimized. (J Thorac Cardiovasc Surg 2010;140:850-6)
\end{abstract}

\section{Supplemental material is available online.}

Fontan repair of a functional single ventricle is performed using a staged surgical approach. This strategy, which has evolved on a clinical basis, remains problematic. ${ }^{1}$ Although stage II volume unloading of the single ventricle provides early partial ventricular volume reduction and improvement in hypoxemia, counter to assumptions, it is not associated

From the Department of Surgery, ${ }^{\text {a }}$ Section of Cardiothoracic Surgery, the James Whitcomb Riley Hospital for Children, Indiana University School of Medicine, Indianapolis, Ind; and Department of Surgery, ${ }^{\mathrm{b}}$ Cleveland Clinic Foundation, Cleveland, Ohio.

Supported by National Institutes of Health Grant HL080089 (MDR), Research Support Funds Grant, IUPUI (MDR), Riley Children's Foundation grant 08-05 (MDR), and National Institutes of Health Grant C06 RR10601 (facility support). Disclosures: None.

Presented in part at the Pediatric Academic Societies and Asian Society for Pediatric Research Joint Meeting, May 2008, Honolulu, Hawaii (CDM).

Received for publication Oct 23, 2009; revisions received Feb 5, 2010; accepted for publication April 10, 2010; available ahead of print May 19, 2010.

Address for reprints: Mark D. Rodefeld, MD, Associate Professor of Surgery, Section of Cardiothoracic Surgery, Indiana University School of Medicine, Emerson Hall 215, 545 Barnhill Drive, Indianapolis, IN 46202 (E-mail: rodefeld@iupui.edu).

$0022-5223 / \$ 36.00$

Copyright (c) 2010 by The American Association for Thoracic Surgery doi:10.1016/j.jtcvs.2010.04.015 with improved late ventricular function or exercise performance. ${ }^{2}$ Thus, the majority of the benefit of interim staging exists early, likely from take-down of the systemic-to-pulmonary arterial shunt. Furthermore, evidence increasingly suggests that early Fontan conversion is associated with improved long-term ventricular function, incidence of normal sinus rhythm, and freedom from atrioventricular valve insufficiency (all presumably secondary to decreased interval of ventricular volume overload). ${ }^{1,2}$ This is consistent with current trends toward earlier repair. Because Fontan conversion at an early age may improve long-term outcome by limiting the period of ventricular volume overload and hypoxemia associated with an interim-staged approach, the best long-term status may derive from avoidance of ventricular volume load or use of a shunt altogether, thus, early primary repair. ${ }^{3}$

In select patients, Fontan conversion can be performed in 1 stage with excellent results. ${ }^{4}$ This has fallen out of favor because of improved safety margin and early outcomes achieved with interim palliation (earlier take-down of the systemic arterial shunt, with partial improvement in hypoxemia, partial reduction in ventricular volume load, and partial return to series circulation). Perhaps more important, however, staged conversion imposes less physiologic stress on the systemic venous, capillary, and interstitial circulation with partial (superior vena cava [SVC]), rather than global 

Abbreviations and Acronyms
Aorta $_{\text {sat }}=$ aortic oxygen saturation
IVC = inferior vena cava
$\mathrm{IVC}_{\mathrm{sat}}=$ inferior vena cava oxygen saturation
RAAS = renin-angiotensin-aldosterone system
SVC = superior vena cava
$\mathrm{SVC}_{\text {sat }}=$ superior vena cava oxygen saturation

( SVC + inferior vena cava [IVC]), increase in systemic venous pressure. Because decisions to perform Fontan staging have historically revolved around downstream pulmonary vascular resistance (ironically exacerbated by shunt physiology), the upstream systemic aspects of Fontan conversion have been largely overlooked.

Coupled with these questions, evolving circulatory support concepts are making compression of staging and earlier conversion to Fontan an increasingly realistic consideration. ${ }^{5}$ Temporary mechanical cavopulmonary assist can support the time-limited process of systemic and interstitial adaptation to global increase in systemic venous pressure. Although it may improve the margin of safety for direct Fontan conversion, the duration required to bridge to unsupported Fontan is not known. The goal of this study is to define the physiologic events and timeframe to Fontan steady state, with respect to the systemic circulation.

\section{MATERIALS AND METHODS \\ Animal Model}

Juvenile sheep ( 3 months old, $\mathrm{n}=10$ ) underwent right thoracotomy. The right and left azygous veins were ligated. Transthoracic pressure monitoring lines were placed in the pulmonary artery, aorta, SVC, IVC, right atrium, and left atrium. An ultrasonic flowprobe (Transonic, Ithaca, NY) was placed around the ascending aorta. Percutaneous adjustable vessel occluders (Fine Science Tools, Foster City, Calif) were placed around the juxtacardiac IVC and SVC (Figure 1). During 1-week recovery, normal hemodynamics were maintained. Transthoracic pressures (zeroed at olecranon; head neutral) and cardiac output were monitored daily. Animals were allowed unrestricted access to food and water.

\section{Systemic Venous Pressure Elevation}

On experimental day 0 (day of intervention), baseline hemodynamics were measured. In 6 animals, vena caval occluders were incrementally tightened over 15 to 20 minutes to achieve SVC and IVC pressures of 14 to $15 \mathrm{~mm} \mathrm{Hg}$. This was selected as the upper limit of "normal" systemic venous pressure in patients with Fontan, a range that allows documentation of hemodynamic response with few clinical symptoms. Aortic, SVC, and IVC samples were drawn before and after the pressure increase for oxygen saturation (OSM3 hemoximeter, Radiometer, Westlake, Ohio). Venous pressure was monitored twice daily for 5 days to ensure consistency; beyond day 5 , occluder adjustment was seldom required. Control animals $(n=4)$ were identically monitored, with no manipulation of venous pressure.

\section{Assessment of Cardiac Reserve}

Dobutamine infusion (10 $\mu \mathrm{g} / \mathrm{kg} / \mathrm{min}, 20$ minutes) was used to quantify cardiac reserve at 5 time points: study 1 , experimental day -1 (1 day before venous restriction) for baseline; study 2 , experimental day 3 ; study 3 , day 7 ; study 4, day 14; and study 5, day 21 . Hemodynamic variables were recorded at 5-minute intervals, including 5 minutes after termination. Aortic, SVC, and IVC samples were drawn before and after dobutamine infusion for oxygen saturation.

\section{Cerebral Oximetry}

Cerebral oximetry was monitored using near-infrared spectroscopy (Somanetics Inc, Troy, Mich) in 4 experimental animals at the time of venous pressure increase and during dobutamine challenges.

\section{Circulating Blood Volume}

Blood volume was determined at the time of surgery, the day after venous pressure intervention, and before all dobutamine studies using dilution technique (Evan's Blue dye). ${ }^{6}$ Absorbance of plasma drawn from the SVC was measured using a standard spectrophotometric curve. Total blood volume (milliliters/kilogram) was calculated from plasma volume and hematocrit (blood volume $=$ plasma volume $/(1-$ hematocrit $)$ ). Animals were weighed the same day of blood volume determination.

\section{Neurohormonal Markers}

Serum and plasma were collected for antidiuretic hormone, aldosterone, angiotensin II, epinephrine, norepinephrine, and brain natriuretic peptide determination before administering Evan's Blue dye or dobutamine on studies 1 to 5 , as well as the day after venous pressure increase. Samples were frozen at $-80^{\circ} \mathrm{C}$ and batch analyzed (Anilytics Inc, Gaithersburg, Md).

\section{Statistical Analysis}

Results are reported as mean \pm standard deviation. Data were analyzed by pairwise comparison within and between control and experimental groups, including time factor for all time points, by 2-way analysis of variance with correction for repeated measures using Student Newman-Keuls post hoc test. Cerebral oxygen saturation data were analyzed by regression. Statistical analysis was performed with SigmaStat software (Systat, Richmond, Calif).

The experimental protocol was approved by the Animal Care and Use Committee of the Indiana University School of Medicine. Animals received humane care in accordance with the "Guide for the Care and Use of Laboratory Animals" prepared by the Institute of Laboratory Animal Resources and published by the National Institutes of Health (publication 86-23, revised 1996).

\section{RESULTS}

\section{Hemodynamic Response to Acute Elevation in Systemic Venous Pressure}

The 3-fold elevation in systemic venous pressure was surprisingly well tolerated; only 1 animal became unsteady and needed to lie down. In all instances, venous pressure of at least $12 \mathrm{~mm} \mathrm{Hg}$ was achieved at the initial intervention; goal pressure was achieved in most animals. Pressure adjustments $(4-5 \mathrm{~mm} \mathrm{Hg})$ were common in the afternoon of experimental day 0 , but were subsequently few and minor $(<2-3 \mathrm{~mm} \mathrm{Hg})$. SVC and IVC pressures were maintained at $15 \mathrm{~mm} \mathrm{Hg}$ over the duration of the study (Figure 2). Cardiac index decreased significantly in the experimental group, but normalized by day 14 to control (Figure 3). Systemic arterial blood pressure was not affected by increased systemic venous pressure, although heart rate did decrease significantly in control animals during the last 2 weeks of the study 


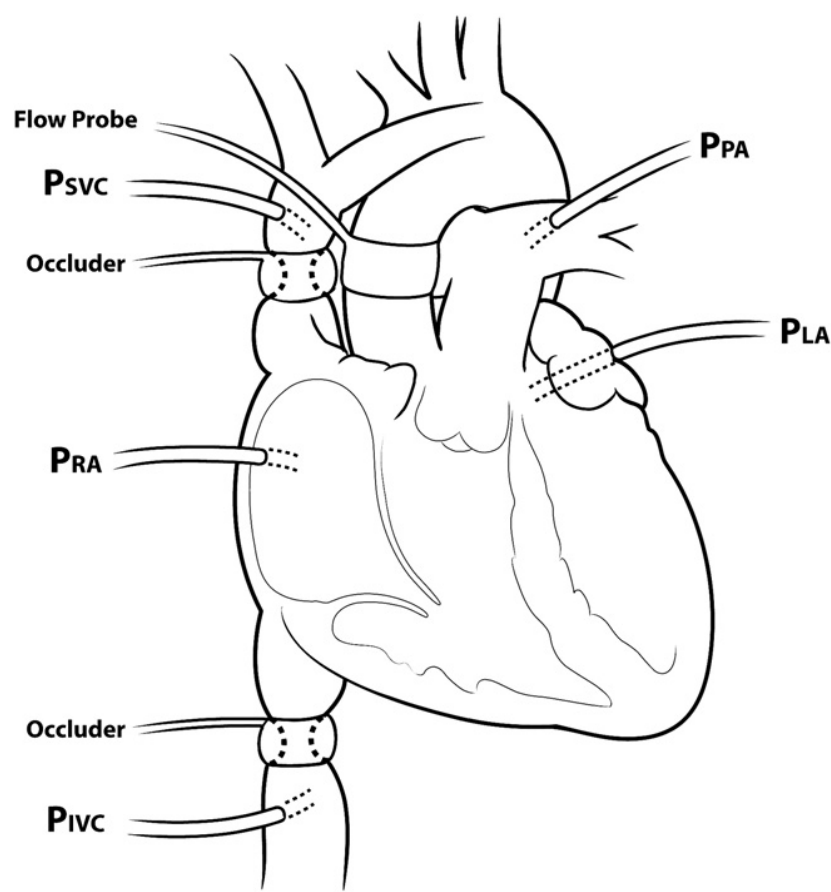

FIGURE 1. Experimental model. $P_{S V C}$, Pressure superior vena cava; $P_{I V C}$, pressure inferior vena cava; $P_{R A}$, pressure right atrium; $P_{L A}$, pressure left atrium; $P_{P A}$, pressure pulmonary artery.

(Table E1). A trend toward lower mean pulmonary arterial pressure in experimental animals reached significance on experimental days $2,4,5,7,8,10$, and 16 . Pulmonary vascular resistance increased in the experimental group in concert with decreased right ventricular preload and cardiac index.

\section{Cardiac Reserve}

A significant heart rate response occurred in both groups to dobutamine infusion, with no between-group difference (Figure E1, $A, B$ ). In the experimental group, cardiac index was significantly decreased in comparison with control at baseline for studies 2 and 3, and after dobutamine for studies 2, 3, and 4 (Figure E1, C, D). Controls had a significant increase in cardiac index from baseline for all 5 studies, but experimental animals did not significantly augment cardiac index in response to dobutamine during studies 2 and 3.

\section{Blood Volume}

Blood volume increased in the experimental group and was significantly higher than baseline on days 3, 7, 14, and 20. Blood volume was significantly higher than control on days 14 and 20 (Figure 4).

\section{Neurohormonal Markers}

Aldosterone and angiotensin II were significantly elevated in the experimental group early after the increase in systemic venous pressure, but normalized to control after week 1 (Figure 5). Antidiuretic hormone also increased
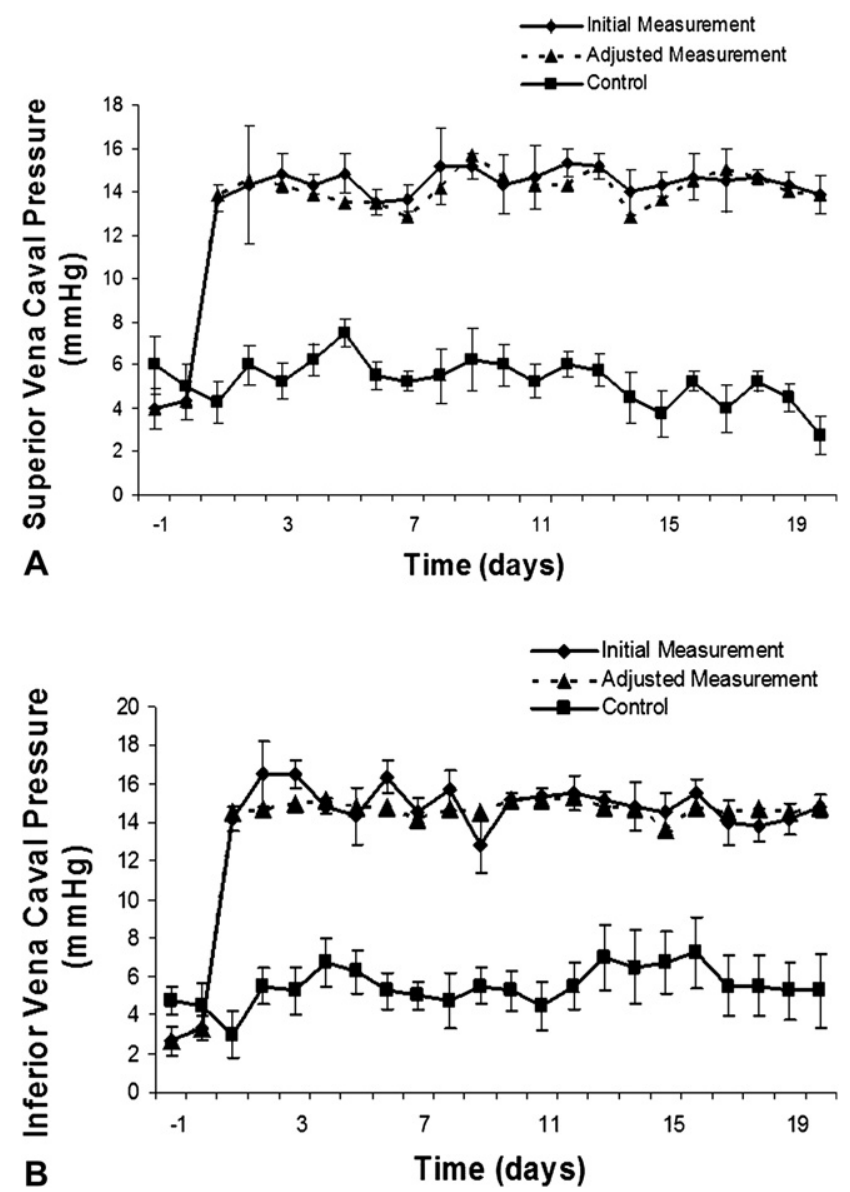

FIGURE 2. Systemic venous pressure: increased and maintained at goal range (14-15 mm Hg) in SVC (A) and IVC (B) distributions days 1 to 20. Adjusted measurement indicates adjustment required in vena caval restriction to maintain measured systemic venous pressure within goal parameters after the initial value at that time interval had been determined.

early, but was not significant (Table E2). No statistical difference was seen in brain natriuretic peptide, epinephrine, and norepinephrine levels in experimental versus control groups (Table E2).

\section{Blood Gases and Cerebral Oximetry}

Aortic oxygen saturation (Aorta sat $_{1}$, SVC oxygen saturation $\left(\mathrm{SVC}_{\mathrm{sat}}\right)$, and IVC oxygen saturation $\left(\mathrm{IVC}_{\mathrm{sat}}\right)$ data are presented in Table E1. SVC $\mathrm{SVat}_{\text {at }}$ was significantly decreased at baseline for studies 2 and 3 , and increased significantly in response to dobutamine during studies 2,3 , and 4 (Figure E2, B). IVC $\mathrm{sat}_{\mathrm{sat}}$ was significantly decreased at baseline for all studies and did not increase in response to dobutamine (Figure E2, D). There was no change in $\mathrm{SVC}_{\text {sat }}$ or $\mathrm{IVC}_{\mathrm{sat}}$ in controls (Figure E2, $A, C$ ). Cerebral saturation increased in response to dobutamine in all cases (Figure E2, $E)$. Oxygen extraction (Aorta $\mathrm{sat}_{\mathrm{sat}}-\mathrm{SVC}_{\mathrm{sat}}$ or $\left.\mathrm{IVC}_{\mathrm{sat}}\right)$ was calculated. Significant group differences in SVC oxygen extraction were seen on days 1, 2, 3, 7 (Figure E3, A). Group 


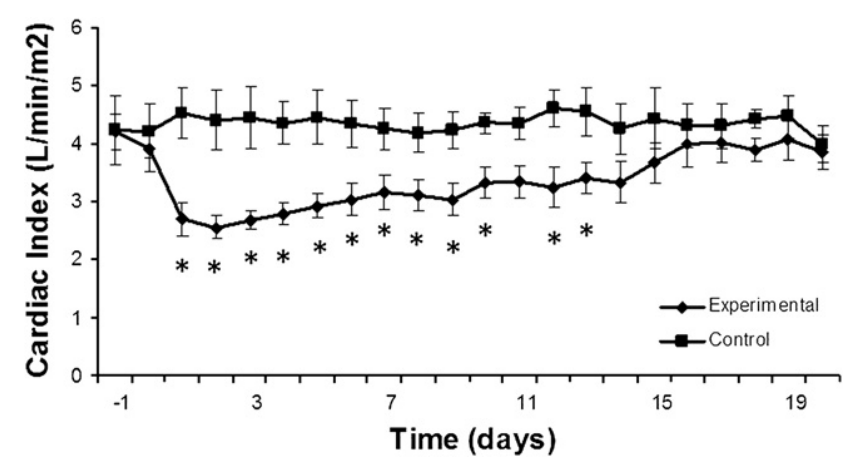

FIGURE 3. Cardiac index: significant reduction after intervention, with normalization by day 14 . *Significant difference between experimental and control groups $(P \leq .05)$.

differences in IVC oxygen extraction were seen on days 2 and 3 (Figure E3, B). Cerebral oximetry correlated with SVC and IVC oxygen saturation both before and after the increase in venous pressure and dobutamine studies. A total of 48 measurements were taken each for cerebral oximetry, $\mathrm{SVC}_{\mathrm{sat}}$ and $\mathrm{IVC}_{\text {sat }}$ using 4 experimental animals. Cerebral oximetry values correlated significantly with $\mathrm{SVC}_{\text {sat }}$ $(\mathrm{R}=0.789, P<.001)$ and $\mathrm{IVC}_{\text {sat }}(\mathrm{R}=0.525, P<.001)$ (Figure E4).

\section{Necropsy}

Left and right azygous vein ligation was confirmed in all cases. There was no evidence of venous thrombus. Small right pleural effusion $(<100 \mathrm{~mL})$ was present in most animals. One animal exhibited significant ascites (6 liters).

\section{Comment}

With increasing numbers of Fontan survivors reaching adulthood, the long-term sequelae of single-ventricle Fontan palliation is now recognized as an emerging public health

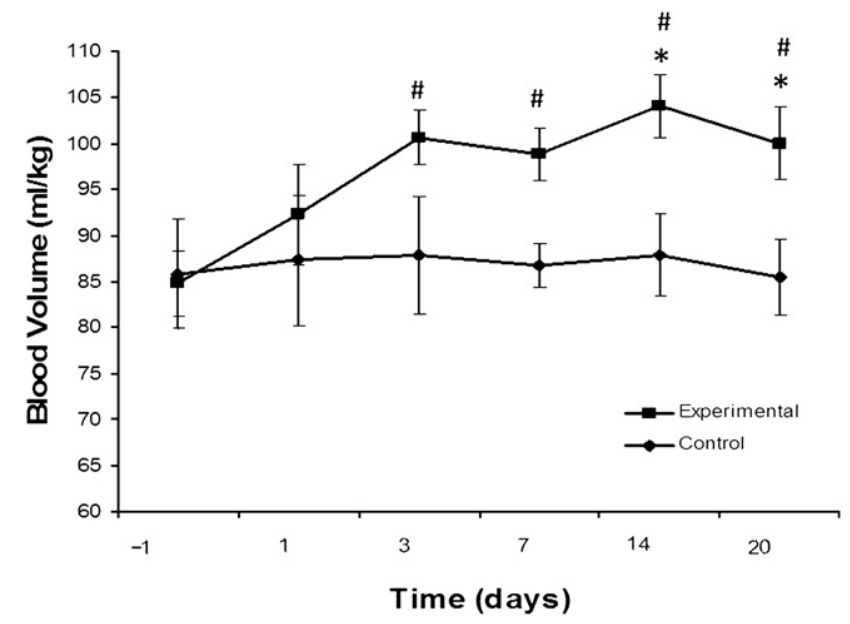

FIGURE 4. Blood volume. *Significant difference $(P \leq .05)$ from control. \#Significant difference $(P \leq .05)$ from baseline.

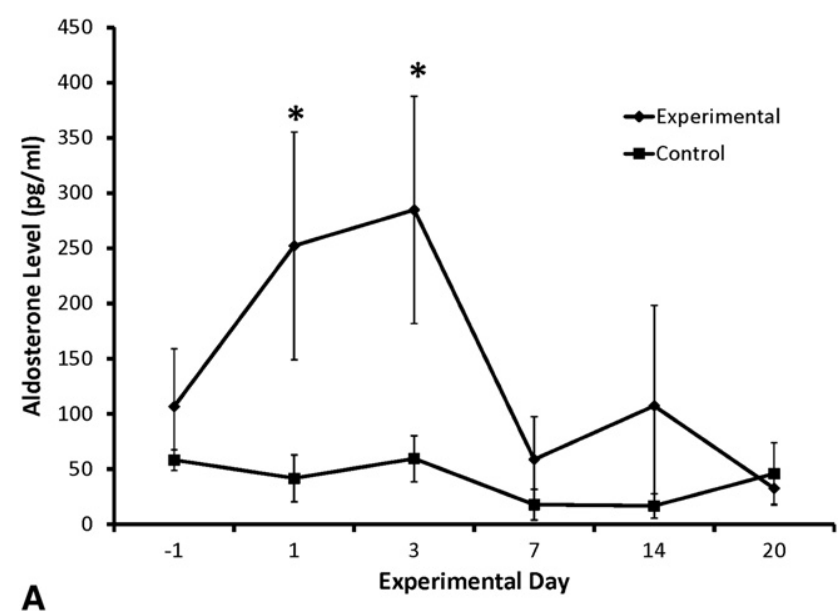

A

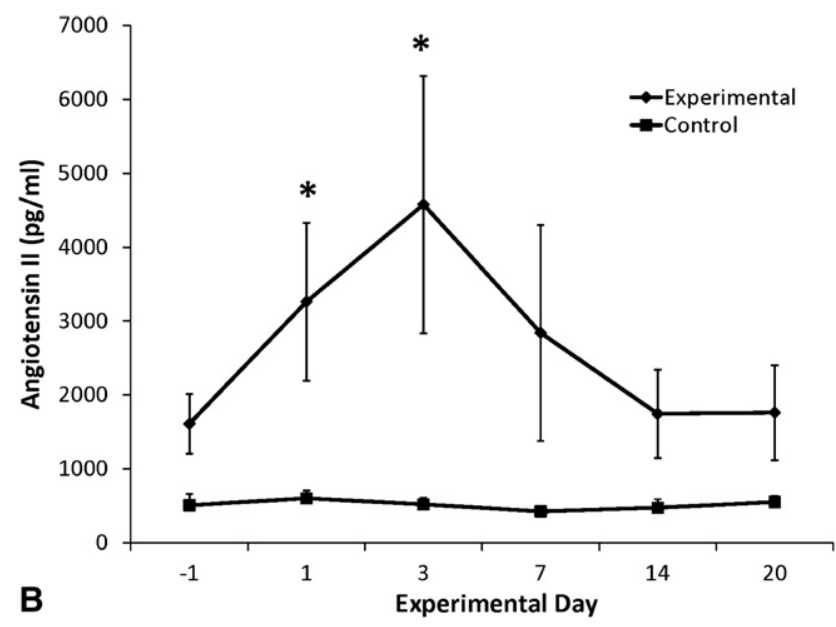

FIGURE 5. Serum aldosterone (A) and angiotensin II (B). *Significant difference $(P \leq .05)$ from control.

concern. ${ }^{7}$ Regression from compensated to uncompensated systemic venous hypertension is integral to the pathogenesis of both early and late Fontan failure. ${ }^{8,9}$ Although long proposed, medical therapies aimed at controlling fluid retention, decreasing pulmonary resistance, and optimizing ventricular function via increased contractility or afterload reduction remain limited and suboptimal.

Systemic compensatory mechanisms undoubtedly play an important role in Fontan homeostasis, including hemodynamic, interstitial, oncotic, neuroendocrine, and reninangiotensin axis regulation. These mechanisms are poorly understood. Venous hypertension, construed as an immutable consequence of Fontan physiology, has been clinically approached as a problem to minimize or avoid. An impediment to objective resolution of this problem is that chronic models of Fontan do not exist; mechanisms underlying Fon$\tan$ homeostasis and failure are not well defined. Complete ${ }^{10}$ and partial right-sided heart bypass ${ }^{11}$ in the context of mechanical support of cavopulmonary flow have been reported, but none have achieved chronic survival, limiting the ability 
to test therapies or draw conclusions beyond the perioperative period.

\section{Hemodynamic Response to Restricted Systemic Venous Return}

In this study, systemic venous pressure was acutely and globally (both SVC and IVC distributions) elevated in awake, conscious animals as a systemic physiologic mimic of 1-stage Fontan conversion. This differs from clinical staged Fontan conversion where pressure elevation in the SVC and IVC distributions are punctual events separated in time and occur in a setting of general anesthesia and cardiopulmonary bypass-associated myocardial dysfunction and capillary leak. Without superimposed capillary leak and third spacing, the findings in this study suggest that 1-stage Fontan conversion may be readily achievable once perioperative fluid shifting is complete and lung parenchymal function is optimized. Normalization of cardiac reserve may reflect a recovered ability to fill the right ventricle as the result of increased preload, although this is not borne out by measured left atrial pressure values. This demonstrates adaptation beyond resting cardiac index, for which increased blood volume presumably plays a key role.

\section{Heart Rate Response to Restricted Systemic Venous Return}

Heart rate disturbances and autonomic dysfunction are well documented late after Fontan. ${ }^{12}$ Sinus node dysfunction and bradycardia have been attributed to surgical injury near the atrial pacemaker complex. In this study, there was no difference in heart rate between control and experimental animals at any time point. There was an overall trend toward decreasing heart rate for both groups that reached significance after week 2 for control animals. The cause of the heart rate decrease is unclear, but it may be attributed to acclimatization to the testing procedures or postsurgical recovery. Both groups retained equivalent ability to increase heart rate in response to dobutamine, with no difference in basal epinephrine and norepinephrine levels, indicating no endogenous catecholamine response to systemic venous restriction. Counter to expectations that an increase in heart rate will occur in response to reduced cardiac output after Fontan, a decrease in heart rate may represent a natural compensatory mechanism aimed to prolong diastolic filling time. It may also be secondary to increased cerebral venous pressure. This has clinical implications for low resting heart rate in patients undergoing the Fontan procedure; recent studies have, in fact, independently associated low resting heart rate with higher functional status. ${ }^{13,14}$

\section{Cerebral Oximetric Response to Restricted Systemic Venous Return}

Despite the inability to increase cardiac index in response to dobutamine, cerebral oximetry values and $\mathrm{SVC}_{\mathrm{sat}}$ increased during dobutamine infusion. $\mathrm{IVC}_{\mathrm{sat}}$ remained unchanged or decreased. This indicates that blood flow is preferentially shifted to the cerebral circulation in response to dobutamine. $\mathrm{SVC}_{\mathrm{sat}}$ and $\mathrm{IVC}_{\mathrm{sat}}$ both correlated well with cerebral oximetry, but oximetry values more closely approximated the change in $\mathrm{SVC}_{\mathrm{sat}}$ in response to dobutamine when initial saturation was subnormal. In agreement with clinical findings, cerebral oximetry strongly predicts $\mathrm{SVC}_{\mathrm{sat}} \cdot 15$

\section{Neuroendocrine Response to Restricted Systemic Venous Return}

The neurohormonal response to intervention includes the following: (1) up-regulation of the renin-angiotensinaldosterone system (RAAS) by increase in angiotensin II and aldosterone, with subsequent normalization beyond 1 week (Figure 5); (2) increased blood volume in the period that RAAS is up-regulated, and which persists after angiotensin II and aldosterone have normalized. Therefore, adaptive mechanisms beyond RAAS up-regulation must remain in play to maintain increased blood volume. There is likely a shift in RAAS over time because its role in chronic Fontan physiology seems to differ from that in the immediate postoperative period.

In animal models, acute and chronic restriction of the IVC alone has been used to induce low cardiac output and an antinatriuretic response. ${ }^{16-18}$ In these studies, diminished cardiac output, ascites formation, increased total peripheral resistance, decreased sodium and potassium excretion, decreased glomerular filtration rate, and antinatriuresis are secondary to decrease in cardiac output and sodium retention mediated by RAAS. RAAS response has been examined clinically early and late after Fontan. RAAS response is up-regulated early after Fontan and bidirectional Glenn cavopulmonary anastomosis ${ }^{19}$ and has been implicated in the development of effusions, but trials using angiotensin-converting enzyme inhibitors have mixed results. Chronically after Fontan, adrenergic tone and RAAS are up-regulated, ${ }^{20}$ although in one study blood volume was not significantly different from biventricular circulations. ${ }^{21} \mathrm{~A}$ randomized controlled trial of angiotensinconverting enzyme inhibitor administration late after Fontan demonstrated no improvement in exercise performance. ${ }^{22}$

\section{Is Staged Palliation the Best Long-Term Strategy?}

Interim staged palliation may represent a trade-off between improved early outcomes, but worsened long-term status. Basal health of the pulmonary vascular bed, in part a reflection of previous staging procedures in which a shunt was used ${ }^{23}$ is the critical inflection point on which ultimate Fontan upstream systemic venous pressure and downstream ventricular filling depend. As a result, a palliative strategy designed to preserve ventricular function and basal pulmonary vascular resistance is of prime importance. Because 
a strategy of shunt palliation and intermediate staging may induce irreversible alterations in the myocardium before volume unloading, it can be argued that this may worsen candidacy for Fontan conversion and long-term functional status. ${ }^{1,2}$ Consideration of approaches that may reduce, or eliminate, use of a shunt or interval staging is timely and clinically relevant, and merits investigation.

\section{The Case for Direct Fontan Repair}

The best strategy may be primary Fontan repair with no staging at all: Precisely how this can be accomplished is a provocative and complex matter. Minimizing or avoiding Fontan staging (combined stage 2 and 3, or stage 1, 2, and 3 Fontan conversion) by performing primary Fontan repair, with temporary mechanical cavopulmonary assist, has compelling theoretic advantages. ${ }^{3,10}$ The interval of ventricular volume overload and hypoxemia is reduced or eliminated, which may reduce the incidence of ventricular hypertrophy and diastolic dysfunction. Also, minimization of hypoxemia and early return to normoxia would reduce the stimulus for pulmonary hypertension and pathologic pulmonary vascular remodeling. Finally, the interstage interval and a second or third open procedure, all significant risk factors for mortality, would be obviated by direct conversion to Fontan.

\section{Duration of Support as Bridge to Fontan}

Adaptation to Fontan venous pressure is complete within 2 weeks; this is a reasonable duration within which percutaneous mechanical circulatory support can be applied. During support, 2-ventricle physiologic conditions are replicated, with no unsafe upper limit to oxygenation, a more stable series circulation, and no ventricular volume overload. An obvious concern is risk of elevated pulmonary resistance in newborns. However, in normal human neonates, pulmonary resistance decreases rapidly to within $10 \%$ of adult values within the first 2 to 3 days of life. ${ }^{24,25}$ Experimental data that we have generated in newborn lambs with mechanically assisted cavopulmonary blood flow also support this, with normalization of pulmonary resistance in response to mechanical cavopulmonary assist within 8 hours. ${ }^{3}$ Physiologic details remain to be determined, but, under ideal physiologic conditions, neonates are clearly capable of maintaining low pulmonary resistance. Adjuncts, such as selective pulmonary vasodilators, may facilitate transition from supported to unsupported neonatal Fontan repair of single ventricles.

\section{Study Limitations}

This is not a true model of a Fontan circulation, but rather a model of systemic venous hypertension in a biventricular circulation. Although the model produces chronic elevation in systemic venous pressure, it differs in important ways from a Fontan procedure. The right ventricle is maintained in the circulation, and the downstream resistor to venous re- turn is a fixed anatomic obstruction rather than physiologic pulmonary resistance. Blood is still pumped to the lungs by the right ventricle, rather than being driven passively by systemic venous pressure. The interactions of respiration, gravity, IVC, and hepatic venous and transpulmonary blood flow, all of which are important in the Fontan circulation, are not accounted for. Also, the effects of pulmonary resistance on systemic impedance when added in series to the systemic circulation are not examined or accounted for.

\section{CONCLUSIONS}

Absent an existing chronic model of Fontan, the model provides a reasonable estimate of the systemic transitional events that occur in 1-stage Fontan conversion and may serve for study of systemic Fontan pathophysiology. In this analysis, selective restriction of SVC and IVC return to model intermediate staging was not performed; studies of this nature must account for venous collateral shunting to the opposing unrestricted venous territory. Because the study was performed in juvenile animals, firm conclusions regarding neonatal adaptation to elevated systemic venous pressure cannot be drawn. The findings in this study elucidate the mechanisms of global adaptation to Fontan-level venous pressure and define the time course for this transition to stably occur. This information may be useful to guide optimization strategies for Fontan palliation.

\section{References}

1. Backer CL. The Fontan procedure. Our odyssey continues. J Am Coll Cardiol. 2008;52:114-6.

2. Anderson PA, Sleeper LA, Mahony L, Colan SD, Atz AM, Breitbart RE, et al. Contemporary outcomes after the Fontan procedure. A pediatric heart network multicenter study. J Am Coll Cardiol. 2008;52:85-98.

3. Rodefeld MD, Boyd JH, Myers CD, Presson RG, Wagner WW, Brown JW. Cavopulmonary assist in the neonate: an alternative strategy for single-ventricle palliation. J Thorac Cardiovasc Surg. 2004;127:705-11.

4. Hsu DT, Quaegebeur JM, Ing FF, Silber EJ, Lamour JM, Gersony WM. Outcome after the single-stage, nonfenestrated Fontan procedure. Circulation. 1997 96(suppl II):II-335-40.

5. Rodefeld MD, Coats B, Fisher T, Giridharan GA, Chen J, Brown JW, et al. Cavopulmonary assist for the univentricular Fontan circulation: von Karman viscous impeller pump. Abstract AATS Boston 2009. J Thorac Cardiovasc Surg. 2010;140:529-36.

6. Wamberg S, Sandgaard NC, Bie P. Simultaneous determination of total body water and plasma volume in conscious dogs by the indicator dilution principle. J Nutr. 2002;132:1711S-3.

7. Williams R, Pearson GD, Barst RJ, Child JS, del Nido P, Gersony WM, et al. Report of the National Heart, Lung, and Blood Institute Working Group on Research in Adult Congenital Heart Disease. J Am Coll Cardiol. 2006;47:701-7.

8. Rychik J, Spray TL. Strategies to treat protein-losing enteropathy. Semin Thorac Cardiovasc Surg Pediatr Card Surg Annu. 2002;5:3-11.

9. Marino BS. Outcomes after the Fontan procedure. Curr Opin Pediatr. 2002;14: 620-6.

10. Rodefeld MD, Boyd JH, Myers CD, LaLone BJ, Bezruczko AJ, Potter AW, et al Cavopulmonary assist: circulatory support for the univentricular Fontan circulation. Ann Thorac Surg. 2003;76:1911-6.

11. Tsuda S, Sasaki T, Maeda K, Riemer RK, Reichenbach SH, Reinhartz O. Recovery during mid-term mechanical support of Fontan circulation in sheep. ASAIO J. 2009;55:406-11.

12. Davos CH, Francis DP, Leenarts MF, Yap SC, Li W, Davlouros PA, et al. Global impairment of cardiac autonomic nervous activity late after the Fontan operation. Circulation. 2003;108(Suppl 1):II180-5. 
13. Blaufox AD, Sleeper LA, Bradley DJ, Breitbart RE, Hordorf A, Kanter RJ, et al. Functional status, heart rate, and rhythm abnormalities in 521 Fontan patients 6 to 18 years of age. J Thorac Cardiovasc Surg. 2008;136:100-7.

14. Camposilvan S, Milanesi O, Stellin G, Pettenazzo A, Zancan L, D’Antiga L. Liver and cardiac function in the long term after Fontan operation. Ann Thorac Surg. 2008;86:177-82.

15. Kirshbom PM, Forbess JM, Kogon BE, Simsic JM, Kim DW, Raviele AA, et al. Cerebral near infrared spectroscopy is a reliable marker of systemic perfusion in awake single ventricle children. Pediatr Cardiol. 2007;28: 42-5.

16. Schrier RW, Humphreys MH. Factors involved in antinatriuretic effects of acute constriction of the thoracic and abdominal inferior vena cava. Circ Res. 1971;29: 479-89.

17. Schrier RW, Humphreys MH, Ufferman RC. Role of cardiac output and the autonomic nervous system in the antinatriuretic response to acute constriction of the thoracic superior vena cava. Circ Res. 1971;29:490-8.

18. Lifschitz MD, Schrier RW. Alterations in cardiac output with chronic constriction of thoracic inferior vena cava. Am J Physiol. 1973;225:1364-70.
19. Francois K, Bove T, DeGroote K, Panzer J, Vandekerchove K, Suys B, et al. Pleural effusions, water balance mediators and the influence of lisinopril after completion Fontan procedures. Eur J Cardiothorac Surg. 2009;36:57-62.

20. Inai $\mathrm{K}$, Nakanishi $\mathrm{T}$, Nakazawa $\mathrm{M}$. Clinical correlation and prognostic predictive value of neurohumoral factors in patients late after the Fontan operation. Am Heart J. 2005; 150:588-94.

21. Kelley JR, Mack GW, Fahey JT. Diminished venous vascular capacitance in patients with univentricular hearts after the Fontan operation. Am J Cardiol. 1995; 76:158-63.

22. Kouatli AA, Garcia JA, Zellers TM, Weinstein EM, Mahony L. Enalapril does not enhance exercise capacity in patients after Fontan procedure. Circulation. 1997; 96:1507-12.

23. Khambadkone S, Li J, de Leval MR, Cullen S, Deanfield JE, Redington AN. Basal pulmonary vascular resistance and nitric oxide responsiveness late after Fontantype operation. Circulation. 2003;107:3204-8.

24. Morin FC, Egan E. Pulmonary hemodynamics in fetal lambs during development at normal and increased oxygen tension. J Appl Physiol. 1992;73:213-8.

25. Soifer S, Schreiber M, Heymann M. Leukotriene antagonists attenuate thromboxane-inducible pulmonary hypertension. Pediatr Res. 1989;26:83-7. 


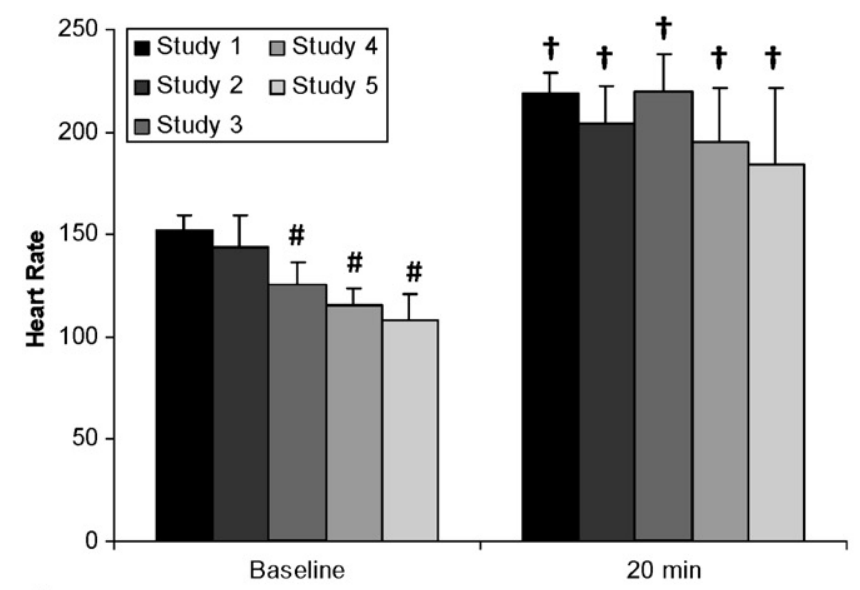

A

Time
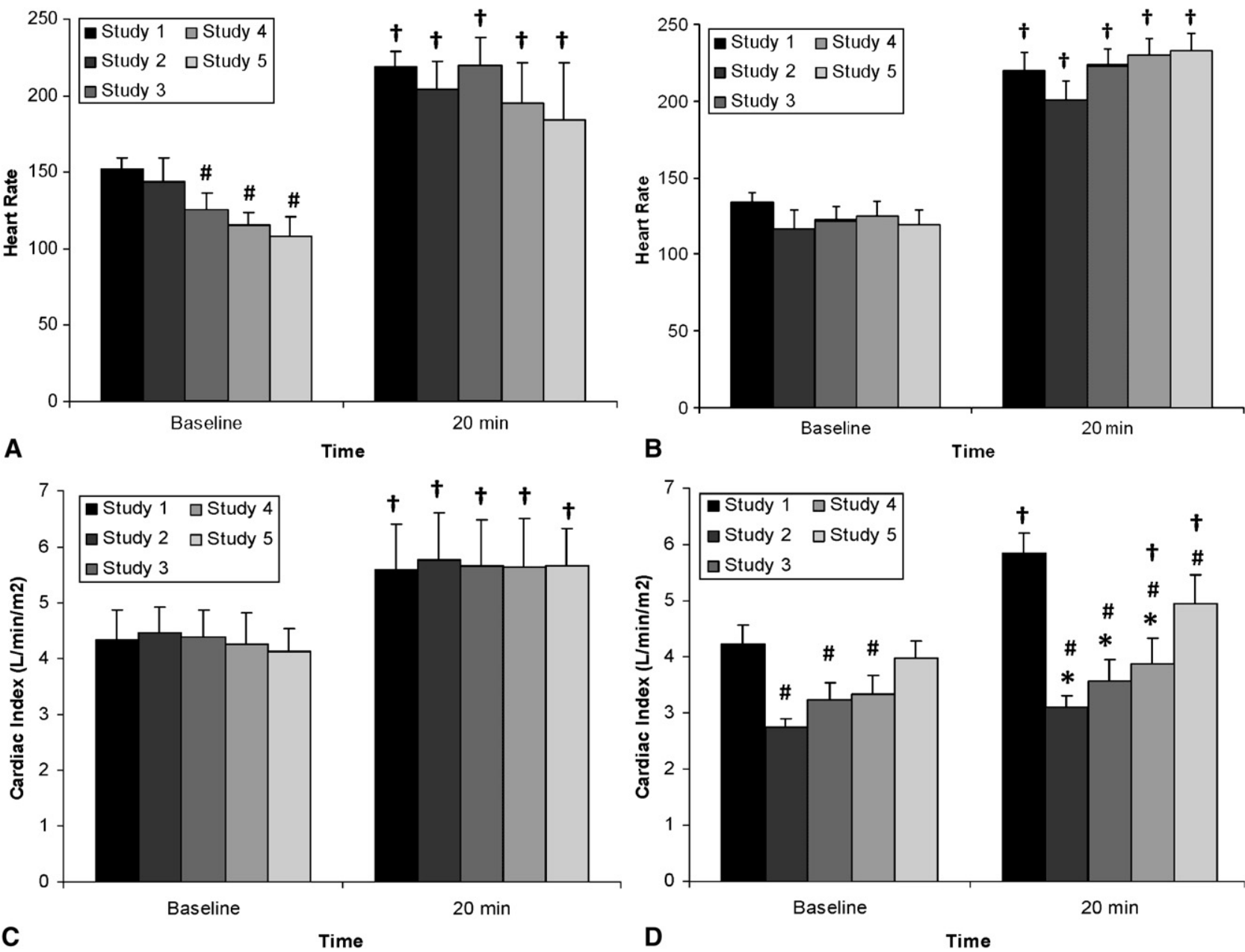

FIGURE E1. Heart rate in control (A) and experimental (B) groups, and cardiac index in control (C) and experimental (D) groups at baseline and after 20-minute dobutamine infusion. Study 1: 1 day before intervention. Study 2: 3 days postintervention. Study 3: 7 days postintervention. Study 4: 14 days postintervention. Study 5: 21 days postintervention. *Significant difference $(P \leq .05)$ from control. \#Significant difference $(P \leq .05)$ from study 1 . $\dagger$ Significant difference $(P \leq .05)$ from baseline. 

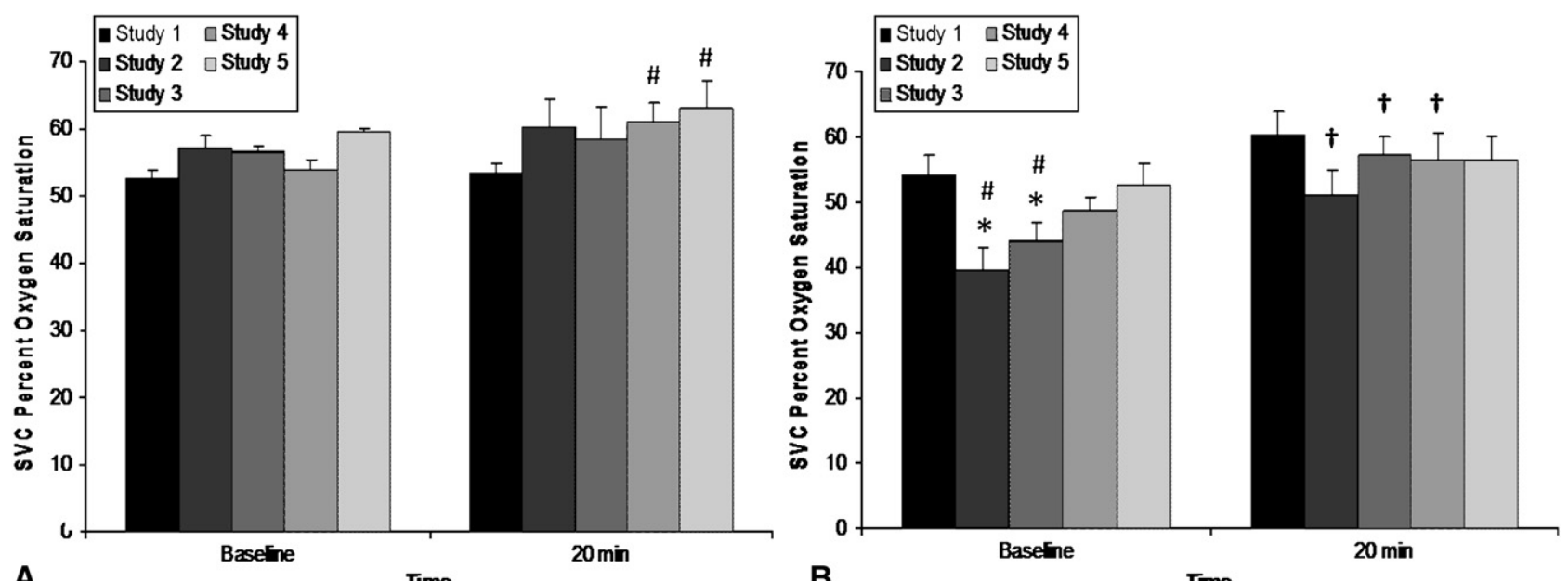

A

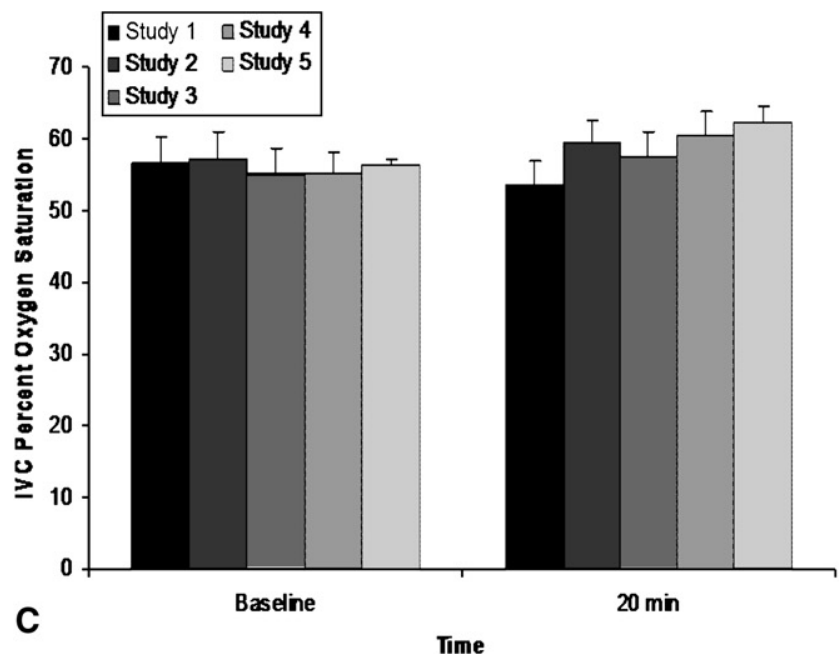

B

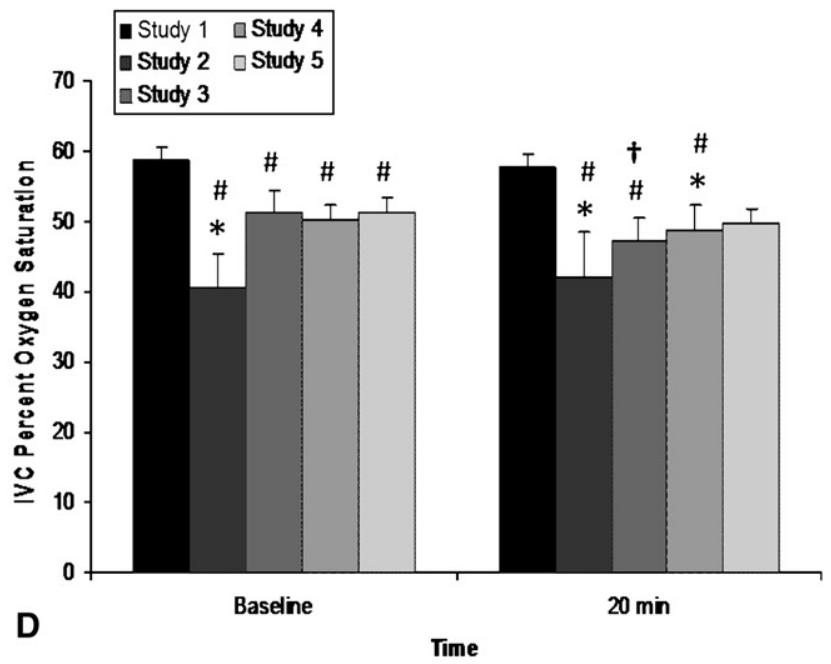

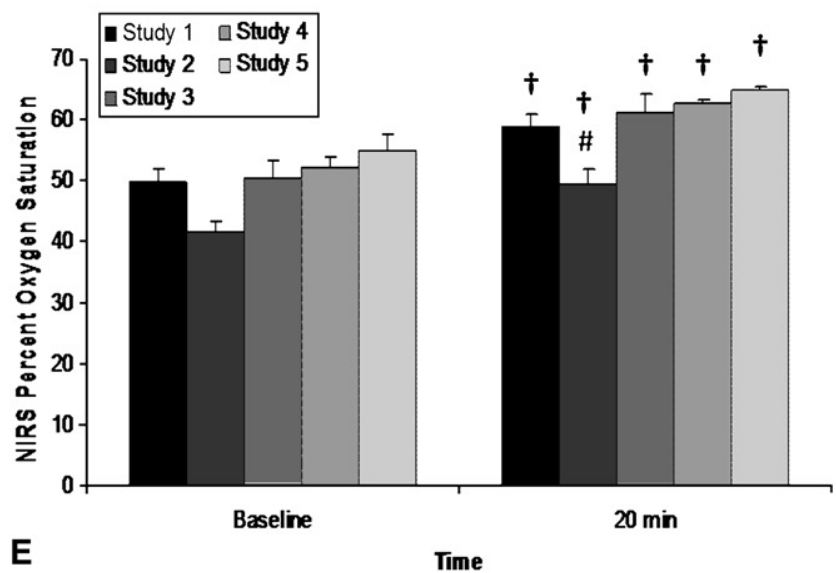

FIGURE E2. Blood oxygen saturation in SVC in control (A) and experimental (B) animals and IVC in control (C) and experimental (D) animals at baseline after 20-minute dobutamine infusion. E, Represents near-infrared spectroscopy measurements in experimental animals $(\mathrm{n}=4)$ at baseline after 20-minute dobutamine infusion. Study 1: 1 day before intervention. Study 2:3 days postintervention. Study 3: 7 days postintervention. Study 4:14 days postintervention. Study 5: 21 days postintervention. *Significant difference $(P \leq .05)$ from control. \#Significant difference $(P \leq .05)$ from study 1 values. $\dagger$ Significant difference $(P \leq .05)$ from baseline. $S V C$, Superior vena cava; $I V C$, inferior vena cava; NIRS, near-infrared spectroscopy. 

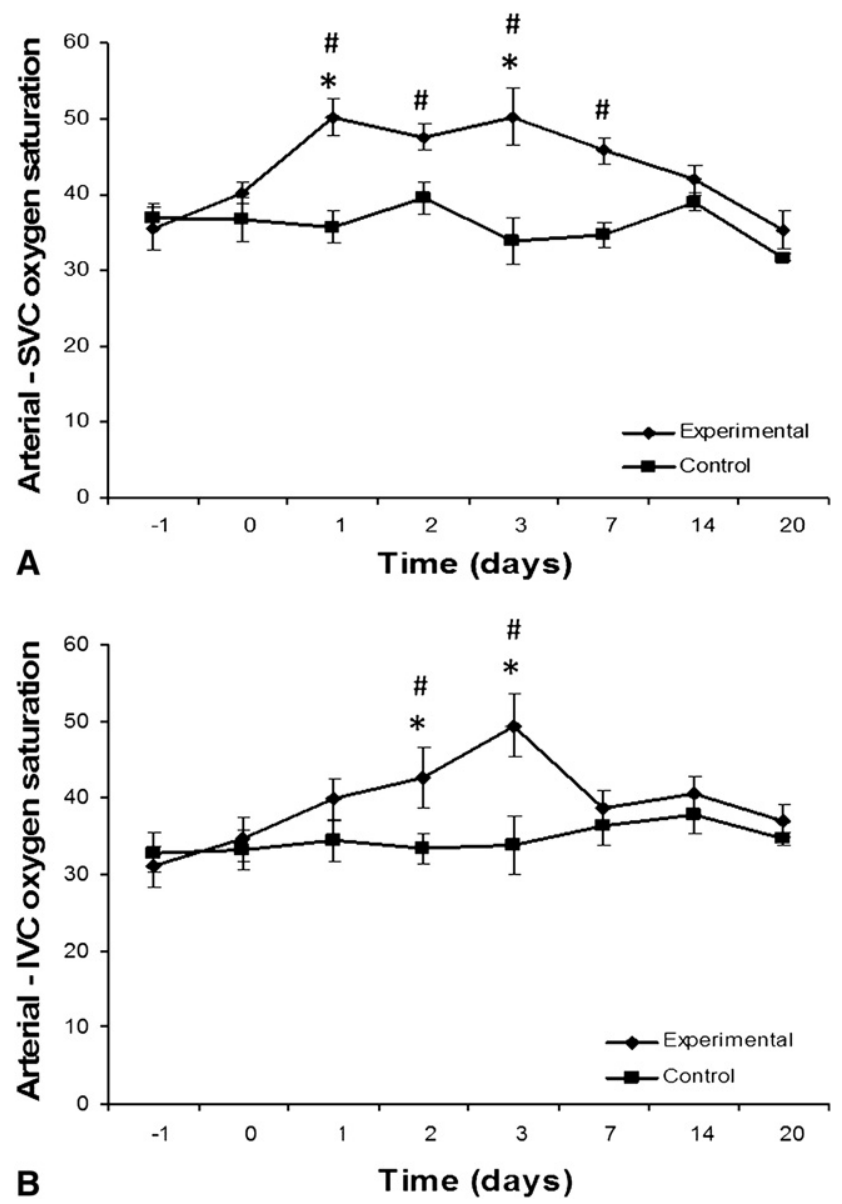

FIGURE E3. Oxygen extraction in the SVC (A) and IVC (B) versus time. *Significant difference $(P \leq .05)$ from control. \#Significant difference $(P \leq .05)$ from baseline. $S V C$, Superior vena cava; $I V C$, inferior vena cava. 

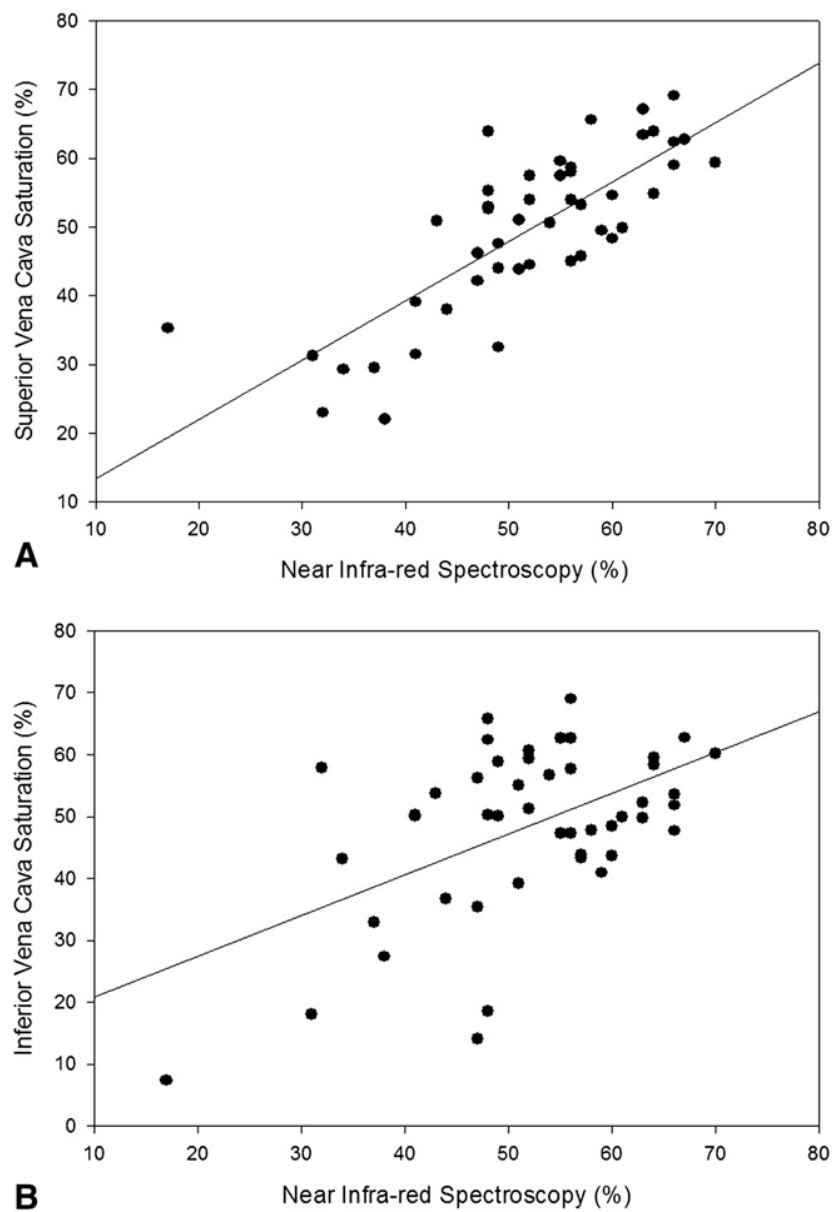

FIGURE E4. Correlation between cerebral near-infrared spectroscopy measurements and SVC (A) and IVC (B) blood oxygen saturation in experimental animals $(\mathrm{n}=4) . P<.001$. 
TABLE E1. Hemodynamic and blood gas data

\begin{tabular}{|c|c|c|c|c|c|c|c|c|c|c|c|c|c|c|}
\hline \multirow[t]{2}{*}{ Parameter } & \multirow[b]{2}{*}{ III } & \multirow{2}{*}{\multicolumn{2}{|c|}{ Group }} & \multicolumn{4}{|c|}{ Baseline (day 0 preintervention) } & \multicolumn{4}{|c|}{ Day 1} & \multicolumn{3}{|c|}{ Day 3} \\
\hline & & & & & lue & & II & & & I & II & Value & I & II \\
\hline \multirow[t]{2}{*}{ Heart rate (beats/min) } & \multirow[t]{2}{*}{.048} & \multicolumn{2}{|l|}{ Control } & \multicolumn{2}{|c|}{$151 \pm 11.6$} & \multicolumn{2}{|r|}{.391} & \multicolumn{2}{|c|}{$145 \pm 18$} & .865 & \multirow[t]{2}{*}{.868} & $138 \pm 39$ & .641 & \multirow[t]{2}{*}{.274} \\
\hline & & \multicolumn{2}{|c|}{ Experimental } & \multicolumn{2}{|c|}{$139 \pm 8.6$} & & & \multicolumn{2}{|c|}{$148 \pm 31$} & .075 & & $122 \pm 31$ & .987 & \\
\hline \multirow{2}{*}{$\begin{array}{l}\text { Systolic blood pressure } \\
\text { (mm Hg) }\end{array}$} & .869 & Control & & & \pm 5 & & .510 & 103 & & .988 & .053 & $100 \pm 7$ & .992 & .130 \\
\hline & & Experime & & & \pm 10 & & & 94 & \pm 10 & .996 & & $93 \pm 9$ & .996 & \\
\hline Diastolic blood pressure & .982 & Control & & & \pm 6 & & & 79 & & & NS & $75 \pm 4$ & & NS \\
\hline$(\mathrm{mm} \mathrm{Hg})$ & & Experime & & & \pm 7 & & & & \pm 12 & & & $70 \pm 9$ & & \\
\hline Superior vena cava pressure & $<.001$ & Control & & & \pm 2 & & .496 & & \pm 2 & .899 & $<.001$ & $5 \pm 2$ & 1.000 & $<.001$ \\
\hline$(\mathrm{mm} \mathrm{Hg})$ & & Experime & & & \pm 2 & & & 14 & & $<.001$ & & $15 \pm 1$ & $<.001$ & \\
\hline Inferior vena cava pressure & $<.001$ & Control & & & \pm 2 & & .339 & & \pm 2 & .199 & $<.001$ & $5 \pm 3$ & .999 & $<.001$ \\
\hline$(\mathrm{mm} \mathrm{Hg})$ & & Experime & & & \pm 2 & & & 15 & & $<.001$ & & $15 \pm 1$ & $<.001$ & \\
\hline Cardiac index (cardiac output/ & $<.001$ & Control & & & \pm 0.9 & & .547 & 4.5 & \pm 0.9 & 1.000 & .001 & $4.4 \pm 1.1$ & 1.000 & .002 \\
\hline $\begin{array}{l}\text { weight, expressed in units } \\
\left.\mathrm{L} / \mathrm{min} / \mathrm{m}^{2}\right)\end{array}$ & & Experime & & & \pm 1.0 & & & 2.7 & $t 0.7$ & $<.001$ & & $2.7 \pm 0.4$ & $<.001$ & \\
\hline Mean pulmonary arterial & .960 & Control & & & \pm 2 & & .156 & 16 & & .935 & .351 & $17 \pm 1$ & .970 & .139 \\
\hline pressure $(\mathrm{mm} \mathrm{Hg})$ & & Experime & & & \pm 2 & & & 15 & & .999 & & $15 \pm 2$ & .995 & \\
\hline Right atrial pressure $(\mathrm{mm} \mathrm{Hg})$ & .169 & Control & & & \pm 2 & & & 1.3 & \pm 2.3 & & NS & $2 \pm 2.6$ & & NS \\
\hline & & Experime & & & \pm 1.8 & & & -0.8 & \pm 1.9 & & & $0.4 \pm 4$ & & \\
\hline Left atrial pressure $(\mathrm{mm} \mathrm{Hg})$ & .119 & Control & & & \pm 2.1 & & & 2.5 & \pm 1.9 & & NS & $1.8 \pm 2.2$ & & NS \\
\hline & & Experime & & & \pm 2.2 & & & 0.8 & & & & $0.7 \pm 2.7$ & & \\
\hline Pulmonary vascular & .001 & Control & & & \pm 2.6 & & .827 & 8.6 & \pm 1.9 & .999 & .021 & $9.9 \pm 4.0$ & 1.000 & .058 \\
\hline $\begin{array}{l}\text { resistance, calculated as } \\
\left(\mathrm{P}_{\mathrm{PA}}-\mathrm{P}_{\mathrm{LA}}\right) \times 80 / \text { (cardiac } \\
\text { output } / \text { weight }), \text { expressed } \\
\text { as } 10^{3} \text { dynes } / \mathrm{cm}^{-5} / \mathrm{kg}\end{array}$ & & Experime & & & \pm 3.2 & & & 14.8 & \pm 4.9 & .027 & & $14.8 \pm 4.7$ & .025 & \\
\hline Arterial oxygen saturation $(\%)$ & .255 & Control & & & \pm 4.7 & & & 90.1 & \pm 2.4 & & & $91 \pm 4.4$ & & \\
\hline & & Experime & ntal & 89. & \pm 5.2 & & & 90.3 & \pm 2.0 & & & $89.8 \pm 2.6$ & & \\
\hline SVC oxygen saturation $(\%)$ & .001 & Control & & 52 & \pm 2.8 & & .651 & 54.4 & \pm 4.0 & .984 & $<.001$ & $57.1 \pm 3.7$ & .839 & $<.001$ \\
\hline & & Experime & & 54. & \pm 7.5 & & & 40.1 & \pm 7.5 & $<.001$ & & $39.6 \pm 8.7$ & $<.001$ & \\
\hline IVC oxygen saturation ( $\%)$ & $<.001$ & Control & & 56. & \pm 7.1 & & .678 & 55.7 & \pm 5.0 & .947 & .287 & $57.2 \pm 7.7$ & .873 & .003 \\
\hline & & Experime & & 58. & \pm 4.6 & & & 50.6 & \pm 7.2 & .018 & & $40.5 \pm 12.4$ & $<.001$ & \\
\hline Plasma volume (mL/kg) & .059 & Control & & 85. & \pm 12 & & .876 & 87.3 & \pm 14 & .945 & .444 & $87.8 \pm 13$ & .972 & .058 \\
\hline & & Experime & & 84. & \pm 8.7 & & & 92.3 & \pm 13 & .059 & & $100.7 \pm 7.3$ & .002 & \\
\hline & & & & & ay 7 & & & & ay 14 & & & Day & y 21 & \\
\hline Parameter & & roup & & lue & $\mathbf{I}$ & II & $\mathbf{V a}$ & & $\mathbf{I}$ & & II & Value & $\mathbf{I}$ & II \\
\hline Heart rate (beats/min) & Cont & & 128 & \pm 21 & .458 & .827 & 111 & $=11$ & .028 & & .89 & $103 \pm 23$ & .006 & .297 \\
\hline & Expe & rimental & 124 & \pm 15 & .972 & & 113 & $=16$ & .908 & & & $119 \pm 20$ & .967 & \\
\hline Systolic blood pressure & Cont & & & \pm 5 & .657 & .762 & 98 & & .898 & & .844 & $99 \pm 9$ & .949 & .303 \\
\hline$(\mathrm{mm} \mathrm{Hg})$ & Expe & rimental & & \pm 8 & 1.000 & & 97 & & .954 & & & $94 \pm 4$ & .997 & \\
\hline Diastolic blood pressure & Cont & & & \pm 3 & & NS & 76 & & & & NS & $75 \pm 6$ & & NS \\
\hline$(\mathrm{mm} \mathrm{Hg})$ & Expe & rimental & & \pm 8 & & & 75 & & & & & $71 \pm 5$ & & \\
\hline Superior vena cava pressure & Cont & & & \pm 1 & .999 & $<.001$ & & & .880 & & .001 & $3 \pm 2$ & .316 & $<.001$ \\
\hline$(\mathrm{mm} \mathrm{Hg})$ & Expe & rimental & & \pm 1 & $<.001$ & & 14 & & $<.001$ & & & $14 \pm 2$ & $<.001$ & \\
\hline Inferior vena cava pressure & Cont & & & \pm 1 & .993 & $<.001$ & & $=4$ & .955 & & .001 & $5 \pm 4$ & .998 & $<.001$ \\
\hline$(\mathrm{mm} \mathrm{Hg})$ & Expe & rimental & & \pm 1 & $<.001$ & & 15 & & $<.001$ & & & $15 \pm 1$ & $<.001$ & \\
\hline Cardiac index (cardiac output/ & Cont & & & \pm 0.7 & 1.000 & .038 & 4.2 & $=0.9$ & .999 & & .074 & $4.0 \pm 0.6$ & .775 & .789 \\
\hline $\begin{array}{l}\text { weight, expressed in units } \\
\mathrm{L} / \mathrm{min} / \mathrm{m}^{2} \text { ) }\end{array}$ & Expe & rimental & & \pm 0.7 & .129 & & 3.3 & $=0.9$ & .302 & & & $3.9 \pm 0.7$ & .977 & \\
\hline Mean pulmonary arterial & Cont & & & \pm 4 & .718 & .023 & 17 & & .965 & & .124 & $17 \pm 1$ & .990 & .194 \\
\hline pressure $(\mathrm{mm} \mathrm{Hg})$ & Expe & rimental & & \pm 3 & .944 & & 15 & & .995 & & & $15 \pm 2$ & .981 & \\
\hline Right atrial pressure $(\mathrm{mm} \mathrm{Hg})$ & Cont & & & \pm 3.2 & & NS & 2.3 & $=3.5$ & & & NS & $2.7 \pm 2.3$ & & NS \\
\hline & Expe & rimental & -0.2 & \pm 1.8 & & & -0.2 & $=2.5$ & & & & $1.4 \pm 1.7$ & & \\
\hline
\end{tabular}


TABLE E1. Continued

\begin{tabular}{|c|c|c|c|c|c|c|c|c|c|c|}
\hline \multirow[b]{2}{*}{ Parameter } & \multirow[b]{2}{*}{ Group } & \multicolumn{3}{|c|}{ Day 7} & \multicolumn{3}{|c|}{ Day 14} & \multicolumn{3}{|c|}{ Day 21} \\
\hline & & Value & $\mathbf{I}$ & II & Value & $\mathbf{I}$ & II & Value & $\mathbf{I}$ & II \\
\hline \multirow[t]{2}{*}{ Left atrial pressure (mm Hg) } & Control & $3.5 \pm 2.6$ & & NS & $3 \pm 2.8$ & & NS & $3.3 \pm 3.2$ & & NS \\
\hline & Experimental & $0 \pm 1.3$ & & & $0 \pm 0.6$ & & & $2.5 \pm 2.6$ & & \\
\hline \multirow[b]{2}{*}{$\begin{array}{l}\text { Pulmonary vascular } \\
\text { resistance, calculated as } \\
\left(\mathrm{P}_{\mathrm{PA}}-\mathrm{P}_{\mathrm{LA}}\right) \times 80 /(\text { cardiac } \\
\text { output } / \text { weight }) \text {, expressed as } \\
10^{3} \text { dynes } / \mathrm{cm}^{-5} / \mathrm{kg}\end{array}$} & Control & $10.7 \pm 4.1$ & .999 & .134 & $9.3 \pm 3.4$ & 1.000 & .159 & $9.5 \pm 2.5$ & 1.000 & .895 \\
\hline & Experimental & $14.5 \pm 5.1$ & .036 & & $12.8 \pm 3.8$ & .308 & & $9.2 \pm 3.1$ & .941 & \\
\hline \multirow[t]{2}{*}{ Arterial oxygen saturation $(\%)$} & Control & $91.4 \pm 3.9$ & & & $92.8 \pm 1.3$ & & & $91.2 \pm 0.6$ & & \\
\hline & Experimental & $90 \pm 2.9$ & & & $90.6 \pm 2.5$ & & & $88.1 \pm 2.7$ & & \\
\hline \multirow[t]{2}{*}{ SVC oxygen saturation (\%) } & Control & $56.7 \pm 1.3$ & .009 & .001 & $53.7 \pm 3.4$ & .985 & .165 & $59.5 \pm 0.9$ & .487 & .057 \\
\hline & Experimental & $44.2 \pm 6.9$ & .835 & & $48.7 \pm 5.1$ & .240 & & $52.7 \pm 7.4$ & .516 & \\
\hline \multirow[t]{2}{*}{ IVC oxygen saturation (\%) } & Control & $55.1 \pm 7.4$ & .985 & .436 & $55.1 \pm 6.2$ & .957 & .312 & $56.5 \pm 1.2$ & .817 & .206 \\
\hline & Experimental & $51.3 \pm 7.1$ & .027 & & $50.2 \pm 5.4$ & .018 & & $51.2 \pm 5.0$ & .030 & \\
\hline \multirow[t]{2}{*}{ Plasma volume (mL/kg) } & Control & $86.8 \pm 4.7$ & .841 & .072 & $87.9 \pm 9.1$ & .992 & .020 & $85.5 \pm 8.4$ & .950 & .034 \\
\hline & Experimental & $98.8 \pm 7$ & .002 & & $104 \pm 8.5$ & $<.001$ & & $100 \pm 9.4$ & .002 & \\
\hline
\end{tabular}

$\overline{S V C}$, Superior vena cava; $I V C$, inferior vena cava; $S D$, standard deviation. Values expressed as mean \pm SD. Control group includes $\mathrm{n}=4$ measurements; experimental group includes $\mathrm{n}=6$ measurements for all variables and time points. Columns headed by I are $P$ values for within-group comparisons with baseline. Columns headed by II are $P$ values for between-group comparisons. The column headed by III shows $P$ values for 2 -way analysis of variance group effect for time. Significant $P$ values are in bold.

TABLE E2. Serum neurohormonal markers

\begin{tabular}{|c|c|c|c|c|c|c|c|}
\hline & Group & $\begin{array}{r}\text { Study } 1 \\
(\text { Day -1) } \\
\end{array}$ & $\begin{array}{c}\text { Postintervention } \\
\text { (Day 0) }\end{array}$ & $\begin{array}{l}\text { Study } 2 \\
\text { (Day 3) } \\
\end{array}$ & $\begin{array}{l}\text { Study } 3 \\
\text { (Day 7) } \\
\end{array}$ & $\begin{array}{r}\text { Study } 4 \\
\text { (Day 14) } \\
\end{array}$ & $\begin{array}{r}\text { Study } 5 \\
\text { (Day 21) } \\
\end{array}$ \\
\hline \multirow[t]{2}{*}{$\mathrm{ADH}(\mathrm{pg} / \mathrm{mL})$} & Control & $1.15 \pm 1.11$ & $2.11 \pm 0.9$ & $1.64 \pm 1.13$ & $2 \pm 0.83$ & $2.72 \pm 1.07$ & $2.85 \pm 0.64$ \\
\hline & Experimental & $2.6 \pm 1.03$ & $21.14 \pm 38.64$ & $3.82 \pm 2.31$ & $4.39 \pm 1.82$ & $3.1 \pm 2.31$ & $3.43 \pm 2.09$ \\
\hline \multirow[t]{2}{*}{ Aldosterone (pg/mL) } & Control & $58.2 \pm 18.59$ & $41.68 \pm 42.43$ & $59.44 \pm 41.88$ & $17.82 \pm 27.55$ & $16.62 \pm 22.09$ & $47.78 \pm 56.15$ \\
\hline & Experimental & $106.7 \pm 116.9$ & $252.3 \pm 230.4$ & $284.7 \pm 230.1$ & $58.6 \pm 86.8$ & $107.2 \pm 203.8$ & $32.5 \pm 32.5$ \\
\hline \multirow[t]{2}{*}{ Angiotensin II (pg/mL) } & Control & $506.5 \pm 306$ & $601 \pm 206.8$ & $518.6 \pm 174.1$ & $424.1 \pm 108.4$ & $474.3 \pm 230.9$ & $550.1 \pm 160.7$ \\
\hline & Experimental & $1610.1 \pm 701.3$ & $3261.2 \pm 2394.3$ & $4576.8 \pm 3894.5$ & $2840.6 \pm 2528.7$ & $1745.4 \pm 1337.4$ & $1759.3 \pm 1109.5$ \\
\hline \multirow[t]{2}{*}{$\mathrm{BNP}(\mathrm{ng} / \mathrm{mL})$} & Control & $0.25 \pm 0.03$ & $0.26 \pm 0.06$ & $0.31 \pm 0.08$ & $0.32 \pm 0.12$ & $0.38 \pm 0.12$ & $0.33 \pm 0.1$ \\
\hline & Experimental & $0.3 \pm 0.07$ & $0.22 \pm 0.03$ & $0.21 \pm 0.02$ & $0.27 \pm 0.08$ & $0.27 \pm 0.05$ & $0.28 \pm 0.03$ \\
\hline \multirow[t]{2}{*}{ Epinephrine (ng/mL) } & Control & $0.09 \pm 0.05$ & $0.05 \pm 0.05$ & $0.07 \pm 0.05$ & $0.04 \pm 0.03$ & $0.09 \pm 0.09$ & $0.07 \pm 0.09$ \\
\hline & Experimental & $0.08 \pm 0.03$ & $0.15 \pm 0.09$ & $0.11 \pm 0.07$ & $0.02 \pm 0.02$ & $0.00 \pm 0.01$ & $0.01 \pm 0.02$ \\
\hline \multirow[t]{2}{*}{ Norepinephrine (ng/mL) } & Control & $0.58 \pm 0.29$ & $0.42 \pm 0.22$ & $0.63 \pm 0.22$ & $0.51 \pm 0.38$ & $0.61 \pm 0.5$ & $0.58 \pm 0.44$ \\
\hline & Experimental & $1.25 \pm 0.75$ & $1.2 \pm 0.88$ & $1.48 \pm 1.36$ & $0.97 \pm 0.69$ & $0.22 \pm 0.16$ & $0.47 \pm 0.26$ \\
\hline
\end{tabular}

$A D H$, Antidiuretic hormone; $B N P$, brain natriuretic peptide. Values expressed as mean \pm SD. Control group includes $\mathrm{n}=4$ measurements and experimental group includes $\mathrm{n}=5$ measurements for all variables and time points, except angiotensin II, for which $\mathrm{n}=3$ in the experimental group. 